NBER WORKING PAPER SERIES

DO "SHORTAGES" CAUSE INFLATION?

Owen Lamont

Working Paper 5402

NATIONAL BUREAU OF ECONOMIC RESEARCH

1050 Massachusetts Avenue

Cambridge, MA 02138

December 1995

I thank Ben Bernanke, Olivier Blanchard, David Romer, Matthew Shapiro, Jeremy Stein, and participants at the University of Michigan and the NBER Monetary Economics seminar for helpful comments. I also thank Steve Cecchetti and John Driscoll for providing data, and Amy C. Ko, Kevin Grundy, and Sydney Ludvigson for research assistance. This paper is part of NBER's research program in Monetary Economics. Any opinions expressed are those of the author and not those of the National Bureau of Economic Research.

(c) 1995 by Owen Lamont. All rights reserved. Short sections of text, not to exceed two paragraphs, may be quoted without explicit permission provided that full credit, including () notice, is given to the source. 


\title{
DO "SHORTAGES" CAUSE INFLATION?
}

\begin{abstract}
I count the number of times per month that the word "shortage" appears on the front page of The Wall Street Journal and The New York Times for the period 1969-1994. Using this as a general measure of shortages in the US economy, I test whether shortages help predict inflation. Using a variety of different specifications, I find that this time-series measure of shortages strongly predicts inflation, and contains information not captured by commodity prices, monetary aggregates, interest rates, and other proposed predictors of inflation. This suggests that disequilibrium was an important part of the adjustment of prices to macroeconomic shocks during this period.
\end{abstract}

Owen Lamont

Graduate School of Business

University of Chicago

1101 East 58th Street

Chicago, IL 60637

and NBER 
An equilibrium price vector is one which clears all markets. If for some reason prices do not immediately adjust to changes in demand or supply, markets do not clear: there are shortages or surpluses of goods. Textbook expositions of general equilibrium theory in the absence of a Walrasian auctioneer, for example Varian (1984), discuss the possibility that prices adjust according to a tatonnement process: $\mathrm{dp} / \mathrm{dt}=\mathrm{G}(\mathrm{z}(\mathrm{p}))$, where $\mathrm{p}$ is the price vector, $\mathrm{z}(\mathrm{p})$ is a vector of excess demand, and $\mathrm{G}$ is some signpreserving function of excess demand.

Macroeconomists are also interested in the possibility of sticky prices (e.g., Ball and Mankiw (1993), Blanchard and Kiyotaki (1987), Blinder (1991), Mankiw (1985)). If prices don't adjust, either quantities adjust or markets don't clear. Most recent work on the microfoundations of sticky prices has focused on the first possibility, that quantities adjust. For example, the models in Mankiw (1985) and Blanchard and Kiyotaki (1987) have firms who increase quantities and leave nominal prices fixed when faced with an increase in the money supply. The second possibility, that markets don't clear, has received increasingly less attention as New Keynesian microfoundations for sticky prices has replaced older fixprice assumptions. Blanchard and Fischer (1989) report that interest in disequilibrium dynamics peaked in the late 1970 's.

The idea that price adjustment is not instantaneous but gradual, and results in excess demand, is not restricted to textbooks. Shortages are frequently mentioned in the business press and by policy makers, for example in recent testimony by Alan Greenspan:

"At some point you really do run into restraints...And the way you know that is that deliveries on materials begin to slow down, shortages begin to pop up, and you have all sorts of collateral indications that the system is running into shortages."

...The worry of Mr. Greenspan and other economists is that such tightness, if it persists, will eventually bring on inflation pressures...

- WSJ, page 2, 4/6/95

This paper tests the hypothesis that shortages in goods and service markets cause inflation.

To test this hypothesis, one needs some measure of shortages, which by definition cannot be observed from price and quantity. One way to empirically estimate shortages is through the methods in 
Quandt (1988), which involve estimating a latent variable model using structural demand and supply equations. Another is to look at the "collateral indications" alluded to by Greenspan, which include vendor delivery speeds and measures of unfilled orders.

I attempt instead a frontal attack on the problem of observing shortages. I construct a new measure of shortages, namely the frequency with which the word "shortage" (or variants thereof) appears on the front page of the Wall Street Journal or the New York Times, two national daily newspapers. The basic idea is that, unlike the econometrician, the WSI and NYT are able to observe and report on shortages which affect the national economy.

Section 1 describes the method used to create this measure of shortages, and describes its univariate properties. Section 2 tests whether this shortage measure is statistically related to inflation, using a variety of specifications and types of data. I find that using this measure, shortages are strongly positively correlated with, and strongly Granger-cause, monthly inflation. It appears that this measure of shortages captures information not found in other traditional measures of tightness and other variables and specifications designed to predict inflation. Section 3 concludes.

\section{Data Construction}

The data were constructed using the Nexis database of newspaper article abstracts for the Wall Street Journal and the New York Times. The Nexis database had two main drawbacks. First, over the relevant time period it contained only abstracts, not the full text of article. For an article to be included in the sample, "shortage" had to appear either in the abstract, or the subject classification. ${ }^{1}$ Second, the time period is fairly limited; the Wall Street Journal abstracts run from May 1973 to December 1994, while the New York Times abstracts run from January 1969 to December $1994 .^{2}$

It appeared as if the abstracts grew somewhat more verbose over time.

${ }^{2}$ Unlike the WSJ, the NYT was inconsistently coded over this period. Abstracts were not available after 1980. Subjects were not available prior to 1973. Therefore, the NYT series is based on abstracts from 1969-1973 and on subjects 1973-1994. It did not appear that the slight change in series definition in 
Between 73:5 and 94:12, the word "shortage" appeared in 2582 abstracted articles in the WSJ. ${ }^{3}$ I limited my study to articles which appear on the front page of the newspaper, leaving 509 articles. Some of these articles reported on shortages in other countries (chiefly in the Soviet bloc and in third world countries), and a very small portion reported on non-economic shortages. ${ }^{4}$ After removing articles that were not about shortages in the US economy, a baseline sample of 433 articles remains. ${ }^{5}$ I then created a monthly time series by counting the number of articles that occurred each month. ${ }^{6}$ The New York Times sample was derived similarly.

Table 1 shows summary statistics for both newspapers. Figure 1 shows the shortages measure derived from the Wall Street Journal. ${ }^{7}$ It is immediately obvious from Figure 1 that shortages were largely a phenomenon of the 1970's. Both the level of shortages and the variation fall markedly after 1980 .

The WSJ and NYT shortage series both appear to be stationary, since an augmented Dickey-Fuller test rejected the null hypothesis that there is a unit root. ${ }^{8}$ There appeared to be no seasonal component in either shortage series.

1973:1 was a significant discontinuity, based on the overlap period of 1973-1980.

3 More precisely, I searched for the 8-character string "shortage" so that the word "shortages" would also be found.

${ }^{4}$ In general, the screening procedure erred on the side of inclusiveness. For example, shortages of blood, organs, and priests were all included.

${ }^{5}$ Articles were judgementally deleted if they were primarily about shortages in other countries (or, more rarely, about non-economic shortages). These deletions were clear-cut in articles about the Soviet Union, but somewhat arbitrary in dealing with articles about "world-wide shortages" and OPEC.

${ }^{6}$ I made the data monthly because standard measures of inflation are available at the monthly level. In principle, however, the time series could be daily (or, moving to electronic media such as the Dow Jones news tape, even hourly).

${ }^{7}$ The complete data set is printed in the Appendix.

${ }^{8}$ Using twelve monthly lags and a constant term, the t-statistic was $-4.65<-2.89$ for the WSJ and $-4.11<-2.89$ for the NYT. 
The WSJ is ex ante likely to be a more accurate measure of shortages for two reasons. First, as a business journal, it seems more likely to cover economically important shortages. Second, the NYT covers metropolitan news of the New York area, so that it is a more noisy measure of national shortages. ${ }^{9}$ Therefore, in what follows, I shall focus primarily on the WSI results.

The method used to construct the shortage measure did not require that the article stated that shortages existed; it merely counted the appearance of the word, whether used hypothetically, in past or future tense, positively or negatively, etc.

I did not attempt to systematically classify shortages by product or market. A quick review suggested that many of the shortages in the 1970's were petroleum related. The highest value for the WSJ shortage measure was 19 in January 1974. Of these 19 articles, 18 were about shortages of energy and other petroleum-related products (the non-energy article was about a shortage of paper). The next highest was July 1979 , with 14 articles. Of these 14,11 were about shortages of energy and petroleum products (the other three were about shortages of shepherds, shortages of groceries due to a trucker's strike, and shortage of conversion equipment to convert from oil to gas heat). In the 1980 's, in contrast, more of the shortages appeared to be related to labor. Of the four articles in March 1989, all were about shortages of workers (with one article on a shortage of produce workers, one on a shortage of service workers, and two on a shortage of nurses).

Attempts to gather other text-based measures of excess demand were not successful, since related words appeared far less frequently than the 1.67 monthly appearances of "shortages" in the WSJ. Synonyms for "shortage" which might indicate positive excess demand seemed rare; for example, the word "bottleneck" appeared a grand total of 3 times (or 0.01 times per month) in the WSJ.

9 This is especially the case in the latter half of the sample, when there are very few nationally important shortages. Prior to 1982, the NYT and WSJ series are highly correlated; after 1982, they are essentially uncorrelated. For example, all of the five shortages in 1985:8 NYT relate to local shortages in New York City. 
Antonyms for "shortage" which might indicate negative excess demand were also relatively rare in the WSJ. In an economic context for the US, "surplus" appeared only 0.29 times per month and "glut" appeared only 0.15 times per month. The vast majority of the "surplus" articles referred to a trade surplus or a budget surplus. I conclude from this that either surpluses and gluts of goods and services do not often occur in the US economy, or the Wall Street Journal does not find them newsworthy. If gluts do not occur but shortages do, it may indicate that price adjustment is asymmetric. ${ }^{10}$

\section{Results}

I examined two properties of the shortage measures. First, I tested whether shortages are contemporaneously correlated with inflation. Second, I examined whether shortages have predictive power for future inflation. In both cases I examined different subperiods, different level of time aggregation, and different alternative models. Where possible, I tried to test the properties of the shortage measure in the context of previous research on the empirics of inflation.

\section{Contemporaneous Correlation}

Table 2 reports the coefficients and $t$-statistics from regressions of inflation on the shortage measure from the same period. The regressions also included lagged inflation, and a time trend. The results show that inflation is very strongly, positively correlated with the shortage measure, at the monthly, quarterly, and annual level.

The coefficients from Table 2 show the effect of an increase of one article per month on the inflation rate in percent. So the first entry on the first line shows that if the Wall Street Journal increases the front page appearance of the word "shortage" by one article per month, we would expect to see annualized CPI inflation rise by about 0.32 percentage points.

The last line in Table 2 places the shortage measure into a simple empirical specification from Ball

\footnotetext{
${ }^{10}$ See Ball and Mankiw (1994) for one reason that price adjustment might be asymmetric. Note however that Ball and Mankiw's asymmetry can not explain this pattern: they find with trend inflation prices should be sticky downwards, so we would expect to see gluts not shortages.
} 
and Mankiw (1995) which includes as a regressor "ASYM10," their measure of the asymmetry of relative price changes. The annual shortage measure survives the inclusion of Ball and Mankiw's variable.

\section{Causality Tests}

Table 3 reports Granger-causality tests from shortages to CPI and PPI inflation. Panel A shows standard bivariate regressions and tests whether, given lagged inflation, lagged shortages help predict inflation. The results show that, beyond the shadow of a doubt, shortages Granger-cause inflation at a monthly frequency. At quarterly frequencies, the results are more ambiguous; shortages are significant in two out of four cases (and are near-significant once). Finally, using annual data, last year's shortages appear to be mostly useless in forecasting this year's inflation, although we have at most 25 observations with which to test this hypothesis.

Panels B, C, and D further explore the forecasting ability of shortages at the monthly level, using additional right-hand side variables identified by previous researchers. ${ }^{11}$ The table reports the p-value testing the proposition that shortages have predictive power for inflation in an equation that also includes these other control variables.

Panel B uses specifications from Bernanke (1990), who used interest rate variables to predict inflation. The first line shows the p-value for shortages in an equation which also includes lags of four different interest rate variables, including the federal funds rate (which captures the stance of monetary policy) and the slope of the yield curve (which captures inflationary expectations). ${ }^{12}$ The second line shows the p-value from an equation including only the federal funds rate, which Bernanke found to be the single best predictor of inflation. Shortages are significant in seven out of these eight regressions, and near significant in the last; therefore shortages contain information about future inflation not present in interest

\footnotetext{
${ }^{11}$ I note that both Bernanke (1990) and Rotemberg, Driscoll and Poterba (1991) used CPI inflation and did not investigate PPI inflation, so that their specifications might be more relevant for the CPI.

${ }^{12}$ Fama (1990) and Mishkin (1990) also explores the use of the term structure to predict inflation.
} 
rates.

Panel C uses specifications from Rotemberg, Driscoll and Poterba (1991), who used various monetary aggregates, including the monetary base, $M 2$, and their own proposed currency equivalent, "CE3". Shortages are significant 11 out of 12 times, so that it appears shortages contain information about monthly inflation that is not present in monetary aggregates in this period.

The main conclusion from Table 3, then, is that shortages Granger-cause inflation at a monthly frequency, even conditional on other proposed predictors of inflation.

As shown in Figure 1, shortages were dramatically less evident in the second half of the sample. The 1970's included two oil shocks and were a time of regulation of energy prices by the US government. The disastrous experiment with price controls (1971-74) under the Nixon administration also occurred in this period, and led to widespread shortages (see Gordon (1984) for details).

One concern is, therefore, that the results in Table 3 are driven either by the energy price shocks of the 1970 's or by the Nixon price controls. I look next at these two issues.

\section{Commodity Prices and Inflation}

Since many of the shortages of the 1970 's appear to have been oil-related, it is important to test whether "shortages" just capture the "shortages" of oil. Table 4 explores the question of commodity price shocks and shortages. Is the shortage measure just a proxy for oil prices, or for the fact that oil prices in the U.S. were regulated during this period?

Panel A attempts to control for energy and food commodity price shocks by including lagged measures of commodity price shocks on the right-hand side, in addition to the shortage measure. The first line uses inflation rates for the PPI Food and PPI Fuel indices. These two indices are also used by Ball and Mankiw (1995) to control for commodity price shocks in their study of PPI inflation. The second line uses the inflation rate for the refiners cost of imported petroleum. The third line the ratio of the refiners cost of imported petroleum to the refiners cost of domestic petroleum; this is a measure of the regulation-induced 
price distortion in US oil markets. ${ }^{13}$ If the shortage measure is merely a proxy for regulation-induced price distortion, we might expect the shortage measure to lose its explanatory power in the presence of this variable.

The shortage measure remains significant in four out of these six regressions, and near significant in a fifth. The shortage measure fares worse using the imported/domestic petroleum cost ratio, but here as elsewhere it still significantly Granger-causes CPI inflation. In summary, Panel A shows that for monthly inflation, the shortage measure contains information about future inflation that is not present in commodity price inflation, at least for CPI inflation. Shortages are not just a proxy for oil prices.

Panel B uses, as dependent variables, measures of so-called core inflation which exclude the effects of food and energy prices. ${ }^{14}$ The results in Panel clearly show that the shortage measure contains information about the course of future core inflation at the monthly level. At very high levels of significance the shortage measure Granger-causes inflation excluding food and energy.

Of course, Panel B is not proof that the shortages are not a proxy for oil shocks, since presumably oil prices also lead core inflation. Therefore Panel $\mathrm{C}$ uses core inflation as a dependent variable and the imported/domestic petroleum cost ratio as a control variable. The shortage measure passes this particular test with flying colors. In fact, excluding food and energy from the PPI improves the significance of shortages (after controlling for the imported/domestic petroleum cost ratio) .

Bryan and Cecchetti (1994) have found that the weighted median inflation rate is a good measure of (their definition of) core inflation, in that median inflation is more closely related to money growth and is a good predictor of future inflation. Panel D documents the relationship between the shortage measure and Bryan and Cecchetti's median CPI inflation series. Shortages are more closely related to mean

${ }^{13}$ I thank Matthew Shapiro for suggesting this variable.

${ }^{14}$ These indices are calculated for the Bureau of Labor Statistics, and are seasonally adjusted except for the PPI excluding fuel and food. 
inflation than to median inflation; consequently, shortages are positively correlated with (and significantly Granger-cause) inflation's deviation from median. This result is consistent with the idea that shortages are a transitory, high-frequency phenomena.

Subsample Stability

If the empirical significance of the shortage measure is limited to the decade of the 1970 's, then it will be hard to conclude that shortages are a generally important phenomenon, since we know price controls lead to shortages. Thus the stability of the relationship between shortages and inflation is of particular interest. Table 5 addresses two questions. First, is the inflation-shortage connection limited to the 1970 's, when energy prices were regulated? This first question is another way of addressing the issues in Table 4. Second, is the inflation-shortage connection purely a product of the Nixon price controls?

Table 5 examines the stability of the relationship between WSJ shortages and inflation in different subsamples. I examine Granger causality, the coefficients on lagged shortages, and contemporaneous correlations. For comparison, the last column reports Granger causality tests for inflation over the same subperiods for the growth rate of the M2 monetary aggregate.

Panel A shows that lagged shortages have predictive power for CPI and PPI inflation in the first half of the sample (1974-82) but not in the second (1983-1994). Like M2, the shortage measure is by this reckoning not a robust predictor of inflation in this period..$^{15}$

The importance of these oil-shock years is a common finding in empirical work in inflation, as is the general nonrobustness of time-series relationships in recent macroeconometrics. As noted by Fischer (1981), for example, much of the relationship between relative price variability and inflation comes from

${ }^{15}$ Using the monetary base instead of M2 produces similar results: the monetary base only has predictive power in half the sample. The difference is that the monetary base has power in the first half of the sample but not the second. 
energy and food price changes in these years. ${ }^{16}$ Bernanke (1990) finds that the forecasting power of interest rates for inflation has also deteriorated significantly since 1980.

Why does the predictive ability of shortages break down in Panel A? There are two possibilities: that the parameters change over this period, or that only the standard errors change. As Table 1 reports, the variation in shortages falls markedly after 1980 , so that we would expect standard errors to rise. Panel $B$ reports the sum of the coefficients on 12 months of lagged shortages from Panel A; this sum measures the cumulative effect of shortages on inflation. The parameters are roughly stable over the two halves of the sample, rising from .43 to .81 for the CPI but falling from 1.97 to 1.21 for the PPI. The standard errors rise markedly, as might be expected given the shortage of "shortages" in the latter half of the sample. The stability of the shortages-inflation relation contrasts sharply with the M2-inflation relation.

Panel $\mathrm{C}$ reports contemporaneous correlations between inflation and shortages, and gives us some additional evidence on the stability of the shortages-inflation connection. Unlike lagged shortages, current shortages maintain their statistical significance over both halves of the sample, and again the parameter values are roughly the same.

I conclude, based on panels $\mathrm{B}$ and $\mathrm{C}$, that the reduced form relationship between shortages and PPI and CPI inflation has been fairly stable over time, certainly far more stable than the relationship between M2 and inflation. Unlike M2, we have a good idea why the predictive ability of lagged shortages breaks down: because there very few shortages in the second half of the sample.

Since many of the shortages of the 1980's appear to have been labor shortages, Table 5 also reports on analogous subsample stability statistics for a different type of inflation measure: the rate of change of manufacturing workers hourly earnings. Panel A shows that, unlike CPI and PPI inflation, wage inflation is Granger-caused by shortages in both subperiods. Panel B shows that, like CPI and PPI

${ }^{16}$ Debelle and Lamont (1995) however offer some evidence that, cross sectionally in US cities, the relationship between inflation and relative price variability is not dependent on these years. 
inflation, lagged shortages are positively correlated with wage inflation, and the parameter values are roughly constant over time. Panel C shows that, unlike CPI and PPI inflation, there appears to be no contemporaneous correlation between monthly shortages and monthly wage inflation (for the whole sample, the coefficient is 0.01 ). In sum, the connection between wage inflation and shortages is highly stable over time.

The bottom line from Table 5 is that the relationship between shortages and inflation is not confined to the 1970 's, although it is certainly stronger in the 1970 's for CPI and PPI inflation. There is no evidence that the parameter values change, and contemporaneous shortages are always significantly correlated with PPI and CPI inflation.

Is the explanatory power of the shortage measure driven by the Nixon price controls? On this more narrow question we have a more definite answer from Table 5. Limiting the sample to 1976:11994:12 (well after the Nixon price controls which ended in 1974) does not affect the overall results. Shortages strongly Granger-cause inflation in the post-Nixon period. ${ }^{17}$

\section{Is "shortage" just a synonym for inflation?}

One possible problem with the shortage measure constructed here is that it depends on the precise use of language by journalists. Business reporters might simply use the word "shortage" when they really mean inflation (or perhaps shifts in the supply schedule.) For example, the following was one of the data points: "...buying could push some industries closer to capacity limits, lead to shortages, and force prices up further." (WSI, page 1, 2/17/77). This sentence describes purely hypothetical shortages, and is consistent with a world where shortages never occur in actuality.

If "shortage" is just another word for "inflation", then the shortage measure constructed here might have predictive power because it captures the inflationary expectations of business reporters. To test this hypothesis, I measured the appearance of the "inflation" in the same way that I measured "shortage".

\footnotetext{
${ }^{17}$ I thank David Romer for suggesting this subsample.
} 
Table 6 reports the results.

Panel A shows that, taken in isolation, the word "inflation" has little predictive power. Panel B shows what happens when the regression includes both lagged "inflation" and lagged "shortage". Conditional on monthly "shortage", monthly "inflation" does not have predictive power for inflation at conventional significance levels. Conditional on monthly "inflation," monthly "shortage" does have significant predictive power for inflation. ${ }^{18}$ I therefore conclude from Table 6 that "shortage" is not merely a synonym for inflation. When a Wall Street Journal reporter uses the word "shortage", he or she does something that is statistically distinguishable from using the word "inflation".

\section{Other measures of tightness/shortages}

Table 7 compares the shortage measure with other traditional measures of tightness in the US economy. If the shortage measure used here really does measure economically important shortages, it should be positively correlated with other measures of tightness and negatively correlated with other measures of slack. If on the other hand, it is so correlated with these other measures that it contains no additional information, then we would conclude that the shortage measure is not a useful contribution to economic analysis.

Capacity utilization and industrial production are perhaps the most widely used measures of tightness, and are explicitly used by the Fed to predict inflation. ${ }^{19}$ Unfilled orders and the National Association of Purchasing Manager's vendor performance index are also popular measures. ${ }^{20}$ The WSJ article cited on page 1 discusses the merits of, and the Fed's fondness for, the vendor delivery index as an

${ }^{18}$ Similar results hold for the NYT series. An earlier version of this paper used the NYT data on "inflation" and "shortage" in the period 70:1-80:6 and found that, conditional on monthly "shortage", monthly "inflation" does not have predictive power for inflation at conventional significance levels.

${ }^{19}$ A long tradition uses capacity utilization to explain inflation; see Gordon (1989) for references. Shapiro (1989) finds however that capacity utilization is not helpful in explaining cross-sectional price changes.

${ }^{20}$ Shapiro (1989) discusses both these measures. 
indicator of inflationary pressures. Inventory-sales ratios are included to measure possible stockouts of goods. Overtime hours, the help-wanted advertising index, and the unemployment rate are standard measures of labor market tightness; the regression with the unemployment rate might be interpreted as a Phillips curve. ${ }^{21}$ Finally, the Commerce Department's leading indicators index is included as a summary of economic conditions.

Table 7 tests both the predictive relationship between shortages and these measures, and whether shortages have predictive power for inflation that is not contained in these measures. The first column displays the correlation coefficient of shortages with the candidate measure of tightness. ${ }^{22}$ As expected, shortages are positively correlated with other measures of tightness, such as capacity utilization, unfilled orders, and the slowness of vendor's deliveries. Shortages are negatively correlated with indicators of slack such as the unemployment rate and the inventory-sales ratio.

The next two columns test whether shortages Granger-cause these candidate measures, and whether these candidate measures Granger-cause shortages. In 5 out of 18 cases the candidate measures of tightness Granger-cause the shortage measure. In contrast, shortages have predictive power for the candidate measure in 16 out of 18 cases at the $5 \%$ level and in every case at the $10 \%$ level. Interestingly, shortages appear to be an excellent predictor of output-related series such as employment and industrial production. I leave for future research a full examination of the relationship between shortages and output. The last two columns report on the predictive power of shortages and the candidate variables, in the presence of each other, for PPI inflation. Conditional on the lagged candidate variable, lagged shortages have predictive power at the $5 \%$ level in 13 out of 18 cases and at the $10 \%$ level in all cases. In contrast, the candidate variables have a spotty record (six are significant at the $5 \%$ level and eight are

${ }^{21}$ I thank Olivier Blanchard for suggesting the help wanted index.

${ }^{22}$ This is the standard correlation coefficient, as opposed to the regression coefficient as reported in Table 2. 
significant at the $10 \%$ level).

In terms of consistent Granger-causality, inventory-sales ratios have the best record, since they Granger-cause inflation in the presence of either the WSJ or NYT shortages. In this case, shortages are also significant at the $5 \%$ level. Shortages fare worse in the presence of overtime hours; here the p-values are 0.07 for the WSJ and 0.06 for the NYT.

I conclude from Table 7 that the shortage measure contains information about inflation not present in other measures of "tightness" in the economy. It appears to fairly robust to the inclusion of these other measures, and is always significant at the $10 \%$ level.

\section{Conclusion}

The methodology used here shares some of the features of the "narrative approach" of Romer and Romer (1989), since both involve examining textual evidence. Compared with the "narrative" approach, however, the approach used here is more quantitative and requires less judgement from the empiricist. It might be called the "quantitative textual" approach. Although this approach is new to macroeconomics, it is often used in other disciplines which analyze texts.

This methodology has produced a variable that appears to be strongly related to high frequency movements in inflation. At the very least, then, this paper introduces a useful new variable for forecasting inflation at the monthly level. On the other hand, this variable appears to be less useful in forecasting long-term inflation. Of course, we have only 21 years of WSI data considered here, so making long-term evaluations is difficult. One possible avenue for future research would be collecting more data, since in principle the time series could go back as far as the Wall Street Journal itself.

For shortages to occur, it is necessary but not sufficient that prices be sticky; quantities must also be sticky. The traditional aim of sticky price models has been to show that nominal variables, such as money, can have real effects. But if quantities are sticky, it is no longer clear that nominal money has real effects. It presumably depends whether quantities or prices adjust faster to disequilibria. 
We all know from personal experience that markets do not literally clear perfectly and instantaneously. Prices do not always equilibrate supply and demand; this fact explains the existence of such economic phenomena as restaurant reservations, waiting lists, queues, and stockouts. Whether disequilibrium is empirically important to macroeconomics is another question. The evidence presented here suggests that disequilibrium is an observable part of the dynamic adjustment of prices to macroeconomic shocks, since the shortage measure contains information that is not present in other variables. 


\section{Bibliography}

Ball, Laurence and N. Gregory Mankiw, "A Sticky Price Manifesto," Carnegie-Rochester Conference on Public Policy November 1993.

Ball, Laurence and N. Gregory Mankiw, "Asymmetric Price Adjustment and Economic Fluctuations," Economic Journal March 1994, 104.

Ball, Laurence and N. Gregory Mankiw, "Relative Price Changes as Aggregate Supply Shocks," Quarterly Journal of Economics February 1995, Vol CX Issue 1, pp. 161-194.

Bernanke, Ben S., "On the Predictive Power of Interest Rates and Interest Rate Spreads", New England Economic Review, Nov/Dec 1990, pp. 51-68.

Blanchard, Olivier Jean, and Stanley Fischer, Lectures on Macroeconomics, 1989, The MIT Press, Cambridge MA

Blanchard, Oliver'J., and Nobuhiro Kiyotaki, "Monopolistic Competition and the Effects of Aggregate Demand," American Economic Review 77 (September 1987): 647-66.

Blinder, Alan S. "Why Are Prices Sticky? Preliminary Results from an Interview Study," American Economic Review 81 (May, 1991): 89-96.

Bryan, Michael F. and Stephen G. Cecchetti. "Measuring Core Inflation" in Mankiw, N. Gregory, ed., Monetary Policy, 1994, University of Chicago Press, pp. 195-219.

Debelle, Guy L. and Owen Lamont, "Relative Price Variability and Inflation: Evidence from US Cities," working paper 1995.

Fama, Eugene F., "Term Structure Forecasts of Interest Rates, Inflation and Real Returns," Journal of Monetary Economics. XXV (1990), 59-76.

Fischer, Stanley, "Relative Shocks, Relative Price Variability, and Inflation," Brookings Papers on Economic Activity (1981:2), 381-431.

Gordon, Robert J., Macroeconomics, 3e, 1984, Little Brown and Co., Boston.

Gordon, Robert J., "Assessing the Federal Reserve's Measures of Capacity and Utilization: Comment" Brookings Papers on Economic Activity (1989:2).

Mankiw, N. Gregory, "Small Menu Costs and Large Business Cycles: A Macroeconomic Model of Monopoly," Quarterly Journal of Economics 100 (May 1985):529-37.

Mishkin, Frederick S., "The Information in the Longer Maturity Term Structure about Future Inflation," Quarterly Journal of Economics, Vol CV, No. 442, (August 1990) pp. 815-828.

Quandt, Richard, The Econometrics of Disequilibrium, Basil Blackwell, Cambridge, MA, 1988. 
Romer, Christina D., and David H. Romer, "Does Monetary Policy Matter? A New Test in the Spirit of Friedman and Schwartz" in NBER Macroeconomics Annual 1989, Oliver Jean Blanchard and Stanley Fischer, Eds, The MIT Press, Cambridge MA.

Rotemberg, Julio J., John C. Driscoll, and James M. Poterba, "Money, Output, and Prices: Evidence from a New Monetary Aggregate," 1991, NBER WP \# 3824.

Shapiro, Matthew D., "Assessing the Federal Reserve's Measures of Capacity and Utilization," Brookings Papers on Economic Activity (1989:2), pp. 181-225.

Varian, Hal R., Microeconomic Analysis, 2e, WW Norton, New York, 1984. 
Table 1

Summary Statistics: Monthly Shortages

WSJ and NYT

WSJ

\section{Full Sample}

Sample

No. of months

Mean

$\operatorname{Max}$

Min

Std Dev

Autocorrelation
$73: 4-94: 12$

260

1.67

19

0

2.63

0.70

0.75

312

2.36

48

0
69:1-94:12

\subsection{8}

Notes: Monthly shortages is the number of articles containing the words "shortage" or "shortages" per month. 
Table 2

Contemporaneous Correlation

(t-statistics in parenthesis)

WSJ Shortages

CPI

$73: 5-94: 12$

0.32

(3.95)

0.82

$(5.00)$

73Q2-94Q4

0.39

(3.08)

0.88

(3.65)

73-94

1.02

(4.41)

Ball and Mankiw Specification

\section{NYT Shortages \\ CPI PPI}

69:1-94:12

0.09

(3.15)

0.13

69Q1-94Q4

0.14

(3.01)

69-94

0.60

(5.13)

0.94

(5.57)

Notes: The table reports the coefficient and t-statistic on the contemporaneous value of the shortage measure. All regressions include a constant term and one year of lagged dependent variables, but no lags of shortages; all regressions except the Ball-Mankiw specification include a time trend. The dependent variable is $100^{*}\left(\ln \left(\mathrm{P}_{\downarrow}\right)-\ln \left(\mathrm{P}_{\mathrm{t}-1}\right)\right)$ and is annualized. The last line puts current shortages into the specification of Ball and Mankiw (1994), Table IV, column 2, which includes lagged annual inflation and "Asym10" (a measure of the asymmetry of price changes) on the right-hand side. 
Table 3

Granger Causality Tests

RHS Variable:

LHS Variable:

\section{WSJ Shortages}

CPI
PPI

74:5-94:12
A. Bivariate Regressions

Monthly Data

0.003

74Q2-94Q4

0.20

74-94

0.19
73:11-94:12

Monthly Data

4-RHS VARIABLES

FED FUNDS ONLY
0.08

0.001
NYT Shortages

CPI PPI

C. Rotemberg. Driscoll, and Poterba Specification

$\begin{array}{lllll}\text { Monthly Data } & 74: 5-94: 12 & & 70: 1-94: 12 & \\ \text { MBASE } & 0.02 & 0.01 & 0.03 & 0.004 \\ \text { M2 } & 0.001 & 0.01 & 0.01 & 0.0003 \\ \text { CE-3 (74:5-89:7) } & 0.01 & 0.11 & 0.01 & 0.001\end{array}$

Notes: The p-value tests the hypothesis that lagged shortages do not help predict inflation. All regressions include a constant term, trend, and lagged dependent variables. Panel A: each regression includes one year's worth of lagged dependent variables and lagged shortage variable. Panel B, 4-RHS: following Bernanke (1990) Table 5, Model Size 4, includes six month lags of the federal funds rate, the 6-month commercial paper rate, the spread between the long corporate bond rate and the 10-year treasury bond rate, and the spread between the federal funds rate and the 10-year treasury bond rate. Panel $\mathrm{B}, \mathrm{FF}$ : following Bernanke (1990) model size 1, includes six months lags of the federal funds rate. Panel C: Following RDP, Table 6, includes 12 monthly lags of all variables. CE-3 is a version of RDP's proposed monetary aggregate. 
Table 4

Controlling for Commodity Shocks Using Commodity Prices and Other Measures of Inflation

RHS Variable:

WSJ Shortages

LHS Variable:

CPI

PPI

\section{A. Controlling for Commodity Prices on LHS}

$74: 5-94: 12$

PPI Food, PPI Fuel

0.01

0.01

75:2-94:3

Refiner Cost

0.01

0.06

$75: 1-94: 3$

Imported/Domestic Refiner Cost

0.02

0.16

\section{B. Inflation Excluding Energy and Food on RHS}

PPI ex. energy

$76: 2-94: 12$

0.02

$74: 5-94: 12$

PPI ex. energy and food

0.00

$74: 5-94: 12$

CPI ex. energy and food

0.00001

\section{Inflation Excluding Energy and Food. Controlling for Imported/Domestic Refiner Cost} $76: 2-94: 3$

PPI ex. energy

0.05

$75: 1-94: 3$

PPI ex. energy and food

75:1-94:3

0.01

CPI ex. energy and food

0.00002

\section{Median CPI on LHS}

CPI (Mean)

74:5-92:12

Median CPI

0.004

0.08

Deviation (Mean-Median)

0.05

Notes: All regressions are monthly data is in Table 3a. Panel A: includes on the right-hand side lags of both PPI Fuel and PPI Food inflation, lags of the inflation rate of the refiner cost of imported oil, or lags of the ratio of the refiner cost of imported petroleum to the refiner cost of domestic petroleum. Panels B include as left-hand side variables different PPI and CPI inflation rates as calculated by the Bureau of Labor Statistics. Panel C is identical to Panel B except that it includes lags of the imported/domestic refiner cost ratio as right-hand side variables. Panel D: Median CPI as calculated by Bryan and Cecchetti (1994). "Deviation" is the mean CPI inflation rate minus the median CPI inflation rate. 
Table 5

Subsample Stability

(t-statistics in parenthesis)

RHS Variable:

WSJ Shortages

M2 (Log Differenced)

LHS Variable:

CPI BPI Wages

CPI PPI Wages

\section{A. Monthly Granger Causality Tests}

$\begin{array}{lllllll} & 74: 5-82: 12 & & 74: 5-82: 12 & \\ 74-82 & 0.04 \quad 0.01 & 0.05 & 0.91 \quad 0.14 & 0.92 \\ & 83: 1-94: 12 & & 83: 1-94: 12 & \\ 83-94 & 0.68 \quad 0.38 & 0.01 & & 0.01 \quad 0.64 & 0.46 \\ & 76: 1-94: 12 & & 76: 1-94: 12 & \\ 76-94 & 0.03 \quad 0.01 & 0.0004 & 0.30 \quad 0.91 & 0.30\end{array}$

B. Cumulative Effect

$74: 5-82: 12$

74-82

$\begin{array}{lll}0.43 & 1.97 & 0.35\end{array}$

$\begin{array}{lll}(1.20) \quad(2.80) \quad(1.19) & \end{array}$

83:1-94:12

83-94

$76-94$

$\begin{array}{lll}0.81 & 1.39 & 0.47\end{array}$

$\begin{array}{lll}(1.51) & (1.08) \quad(1.19)\end{array}$

76:1-94:12

$\begin{array}{lll}0.65 & 1.56 & 0.85\end{array}$

$\begin{array}{lll}(2.90) & (3.56) \quad(3.81)\end{array}$
$74: 5-82: 12$

$\begin{array}{lll}-0.11 & -0.52 & -0.25\end{array}$

(0.52) (1.47) (1.14)

83:1-94:12

$\begin{array}{lll}0.57 & 0.71 & 0.21\end{array}$

(3.25) (1.65) (1.05)

76:1-94:12

$\begin{array}{lll}-0.05 & -0.22 & -0.23\end{array}$

$(0.36) \quad(0.88) \quad(1.53)$

\section{Contemporaneous Correlation}

\begin{tabular}{llll} 
& \multicolumn{3}{l}{$73: 5-82: 12$} \\
$73-82$ & 0.27 & 0.82 & -0.05 \\
& $(2.23)$ & $(4.04)$ & $(0.36)$ \\
& $83: 1-94: 12$ & \\
$83-94$ & 0.45 & 1.11 & -0.34 \\
& $(2.04)$ & $(2.01)$ & $(1.22)$ \\
$76-94$ & $76: 1-94: 12$ & \\
& 0.32 & 0.59 & 0.11 \\
& $(3.01)$ & $(2.85)$ & $(0.80)$
\end{tabular}

Notes: Panels A and C: see notes to Tables 2 and 3. Panel B: reports sum of coefficients on lagged shortages from regression in Panel A.

The final three columns reports subsample stability for log-differenced $\mathrm{M} 2$, for comparison only. 
Table 6

"Shortage" vs. "Inflation"

Granger Causality Tests

LHS Variable:

WSI

A. "Inflation" Only

CPI PPI

$74: 5-94: 12$

"Inflation"

$0.48 \quad 0.08$

B. "Inflation" and "Shortage"

$74: 5-94: 12$

"Inflation"

$0.57 \quad 0.47$

"Shortage"

$0.01 \quad 0.05$

Notes: The p-value tests the hypothesis that lagged shortages do not help predict inflation. All regressions include a constant term, trend, and 12 months of lagged dependent variables. Panel A: tests the hypothesis that 12-lags of the number of "inflation" articles does not help predict actual inflation. Panel B: includes both lagged "inflation" and lagged "shortage" in the regression. The first line tests the hypothesis that 12lags of the number of "inflation" articles does not help predict actual inflation, given lagged "shortage" and lagged inflation. The second line tests the hypothesis that lagged "shortage" does not predict actual inflation given lagged "inflation" and lagged inflation. 
Table 7

Other Measures of Tightness/Slack

Monthly PPI Inflation

\begin{tabular}{|c|c|c|c|c|c|}
\hline \multirow[b]{2}{*}{ Capacity Utilization } & \multicolumn{3}{|c|}{ Granger-Causality } & \multicolumn{2}{|c|}{ PPI Inflation } \\
\hline & Corr. & $S$ to $C$ & $C$ to $S$ & $S$ to $\pi$ & $\mathrm{C}$ to $\pi$ \\
\hline WSJ & 0.38 & 0.0003 & 0.06 & 0.07 & 0.001 \\
\hline NYT & 0.27 & 0.0000004 & 0.14 & 0.01 & 0.19 \\
\hline
\end{tabular}

Industrial Production (Log Differenced)

$\begin{array}{llllll}\text { WSJ } & -0.19 & 0.00004 & 0.31 & 0.004 & 0.12 \\ \text { NYT } & -0.16 & 0.00 & 0.79 & 0.001 & 0.04\end{array}$

Unfilled Orders, Durable Mfg, Goods (Log_Differenced)

$\begin{array}{llllll}\text { WSJ } & 0.35 & 0.01 & 0.18 & 0.03 & 0.19 \\ \text { NYT } & 0.22 & 0.01 & 0.01 & 0.02 & 0.05\end{array}$

Vendor Performance Index (Slower Deliveries)

$\begin{array}{llllll}\text { WSJ } & 0.40 & 0.06 & 0.04 & 0.08 & 0.69 \\ \text { NYT } & 0.36 & 0.0004 & 0.0002 & 0.03 & 0.54\end{array}$

Inventory-Sales Ratios. Mfg, and Trade

$\begin{array}{llllll}\text { WSJ } & -0.33 & 0.02 & 0.29 & 0.03 & 0.02 \\ \text { NYT } & -0.20 & 0.08 & 0.12 & 0.01 & 0.002\end{array}$

Mfg. Workers Overtime

$\begin{array}{llllll}\text { WSJ } & -0.05 & 0.02 & 0.02 & 0.07 & 0.04 \\ \text { NYT } & 0.004 & 0.00001 & 0.01 & 0.06 & 0.08\end{array}$

Unemployment Rate

$\begin{array}{llllll}\text { WSJ } & -0.31 & 0.04 & 0.25 & 0.09 & 0.49 \\ \text { NYT } & -0.21 & 0.0002 & 0.30 & 0.004 & 0.47\end{array}$

Help Wanted Index (Log)

$\begin{array}{llllll}\text { WSJ } & 0.04 & 0.002 & 0.57 & 0.01 & 0.07 \\ \text { NYT } & 0.06 & 0.002 & 0.16 & 0.002 & 0.12\end{array}$

Leading Indicators Index ( Log Differenced)

$\begin{array}{llllll}\text { WSJ } & -0.24 & 0.0001 & 0.84 & 0.01 & 0.75 \\ \text { NYT } & -0.23 & 0.000001 & 0.85 & 0.001 & 0.38\end{array}$

Notes: Estimation period is 74:5-94:12 for WSJ and 70:1-80:5 for NYT. S is shortage measure, C is candidate alternative measure for tightness. Every regression includes a time trend, and 12 months lags of all variables. The first column reports the correlation coefficient of the shortage measure, $S$, with the candidate measure, $C$. The next two columns test whether $S$ Granger-causes $C$ and whether $C$ Grangercauses S. The last two columns test whether S or C Granger-cause PPI inflation, in a regression with both lagged $S$ and lagged $C$. 


\section{Fig. 1: WSJ Shortages and CPI Inflation Monthly, 1970-1994}

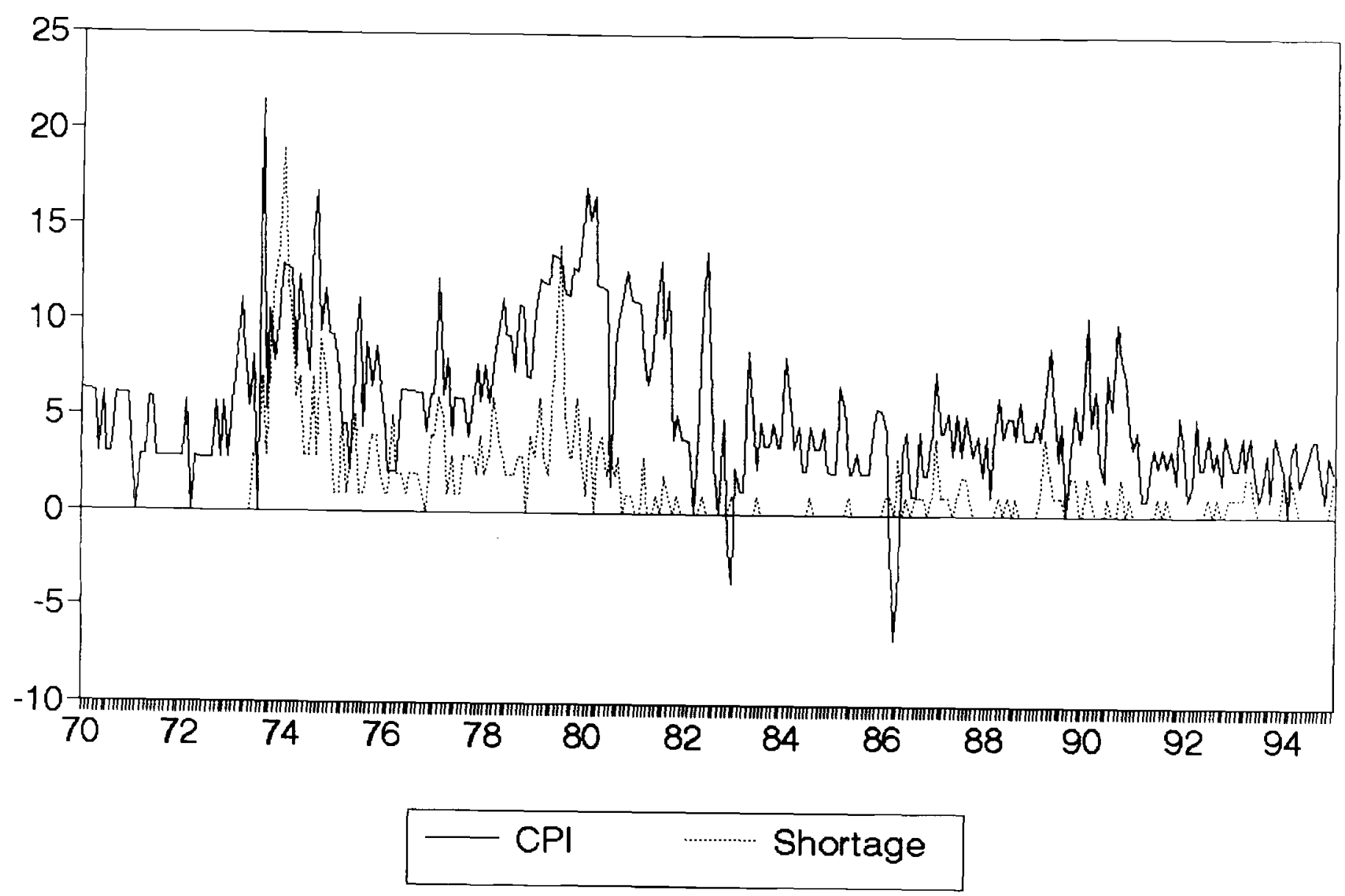


Appendix: Monthly Data on Shortage Measure

$\begin{array}{lllllllllllll}\text { Month } & 1 & 2 & 3 & 4 & 5 & 6 & 7 & 8 & 9 & 10 & 11 & 12\end{array}$

Shortage - NYT

$\begin{array}{rrrrrrrrrrrrr}1969 & 1 & 3 & 2 & 0 & 1 & 3 & 2 & 6 & 6 & 3 & 1 & 7 \\ 1970 & 4 & 3 & 1 & 4 & 1 & 2 & 7 & 6 & 5 & 2 & 3 & 2 \\ 1971 & 3 & 3 & 4 & 1 & 2 & 1 & 5 & 2 & 1 & 0 & 5 & 3 \\ 1972 & 4 & 3 & 1 & 1 & 1 & 2 & 1 & 2 & 0 & 1 & 4 & 4 \\ 1973 & 1 & 0 & 4 & 1 & 1 & 3 & 7 & 7 & 0 & 2 & 23 & 48 \\ 1974 & 30 & 47 & 20 & 5 & 4 & 4 & 1 & 1 & 7 & 7 & 5 & 10 \\ 1975 & 4 & 3 & 0 & 1 & 0 & 3 & 2 & 1 & 2 & 1 & 0 & 1 \\ 1976 & 0 & 3 & 1 & 0 & 1 & 0 & 0 & 0 & 3 & 1 & 0 & 2 \\ 1977 & 24 & 20 & 5 & 2 & 3 & 0 & 3 & 0 & 1 & 2 & 4 & 2 \\ 1978 & 5 & 7 & 3 & 1 & 0 & 1 & 0 & 1 & 0 & 0 & 2 & 0 \\ 1979 & 1 & 6 & 7 & 6 & 25 & 32 & 34 & 9 & 4 & 0 & 0 & 0 \\ 1980 & 2 & 2 & 2 & 1 & 2 & 0 & 0 & 0 & 0 & 1 & 2 & 0 \\ 1981 & 4 & 4 & 0 & 1 & 2 & 0 & 2 & 3 & 0 & 0 & 0 & 0 \\ 1982 & 0 & 0 & 0 & 1 & 0 & 0 & 0 & 0 & 0 & 0 & 0 & 0 \\ 1983 & 0 & 0 & 0 & 0 & 0 & 0 & 0 & 1 & 0 & 1 & 0 & 0 \\ 1984 & 0 & 1 & 2 & 2 & 0 & 2 & 1 & 0 & 0 & 0 & 0 & 1 \\ 1985 & 0 & 0 & 0 & 4 & 0 & 3 & 4 & 5 & 3 & 1 & 1 & 0 \\ 1986 & 2 & 2 & 1 & 1 & 0 & 1 & 2 & 0 & 0 & 0 & 1 & 0 \\ 1987 & 0 & 1 & 0 & 0 & 1 & 1 & 2 & 1 & 1 & 0 & 0 & 1 \\ 1988 & 0 & 2 & 0 & 1 & 1 & 0 & 3 & 0 & 0 & 1 & 1 & 3 \\ 1989 & 1 & 0 & 2 & 0 & 1 & 0 & 1 & 0 & 2 & 1 & 0 & 0 \\ 1990 & 0 & 1 & 1 & 2 & 1 & 0 & 0 & 2 & 2 & 0 & 0 & 2 \\ 1991 & 1 & 0 & 0 & 0 & 0 & 0 & 0 & 0 & 0 & 0 & 1 & 0 \\ 1992 & 0 & 0 & 1 & 0 & 0 & 0 & 0 & 0 & 1 & 0 & 0 & 1 \\ 1993 & 1 & 0 & 0 & 0 & 0 & 0 & 1 & 0 & 0 & 1 & 0 & 0 \\ 1994 & 2 & 2 & 1 & 1 & 3 & 0 & 0 & 0 & 0 & 0 & 1 & 1\end{array}$

Shortage - WSJ

$\begin{array}{rrrrrrrrrrrr}19 & 12 & 10 & 6 & 7 & 3 & 3 & 7 & 3 & 9 & 7 & 5 \\ 1 & 1 & 5 & 1 & 3 & 5 & 1 & 1 & 2 & 4 & 4 & 2 \\ 1 & 1 & 5 & 2 & 2 & 1 & 2 & 2 & 2 & 1 & 0 & 4 \\ 4 & 6 & 5 & 1 & 3 & 1 & 1 & 3 & 3 & 3 & 2 & 4 \\ 2 & 3 & 6 & 4 & 3 & 2 & 2 & 2 & 3 & 3 & 0 & 4 \\ 3 & 6 & 3 & 2 & 5 & 10 & 14 & 5 & 3 & 3 & 6 & 3 \\ 1 & 5 & 0 & 3 & 4 & 2 & 3 & 2 & 3 & 0 & 1 & 1 \\ 0 & 0 & 3 & 0 & 0 & 1 & 0 & 2 & 1 & 0 & 1 & 0 \\ 0 & 0 & 0 & 0 & 1 & 0 & 0 & 0 & 0 & 0 & 0 & 1 \\ 0 & 0 & 0 & 0 & 0 & 1 & 0 & 0 & 0 & 0 & 0 & 0 \\ 0 & 0 & 0 & 0 & 0 & 0 & 1 & 0 & 0 & 0 & 0 & 0 \\ 0 & 0 & 0 & 1 & 0 & 0 & 0 & 0 & 0 & 0 & 0 & 0 \\ 1 & 1 & 0 & 3 & 0 & 1 & 0 & 1 & 1 & 1 & 0 & 1 \\ 4 & 1 & 1 & 1 & 0 & 1 & 2 & 2 & 1 & 0 & 0 & 0 \\ 0 & 0 & 0 & 1 & 0 & 1 & 0 & 1 & 0 & 0 & 0 & 0 \\ 0 & 1 & 4 & 2 & 1 & 1 & 1 & 0 & 2 & 2 & 0 & 0 \\ 2 & 1 & 0 & 0 & 0 & 1 & 0 & 0 & 2 & 0 & 1 & 0 \\ 0 & 0 & 0 & 0 & 0 & 1 & 0 & 1 & 0 & 0 & 0 & 0 \\ 0 & 0 & 0 & 0 & 0 & 1 & 0 & 1 & 0 & 0 & 1 & 1 \\ 1 & 1 & 2 & 2 & 1 & 0 & 0 & 0 & 0 & 0 & 0 & 2 \\ 1 & 2 & 1 & 0 & 0 & 0 & 0 & 0 & 0 & 0 & 0 & 2\end{array}$

